\title{
THE STUDY OF THE SURFACE QUALITY OF THE THIN WALL BEARING UNITS TO ROLLS ROLLER SEATS PIPE CONVEYOR
}

\author{
Peter Michalik' ${ }^{1}$, Jozef Zajac' ${ }^{1}$, Jana Fabianova² ${ }^{2}$ Dusan Mital' \\ 1 The Technical University of Kosice, Faculty of Manufacturing Technologies with a seat in Presov, Slovakia, \\ e-mail: peter.michalik@tuke.sk \\ 2 The Technical University of Kosice, Faculty of Mining, Ecology, Process Control and Geotechnology, Slovakia
}

Received: 2017.04.11

Accepted: 2017.05.04

Published: 2017.06.01

\begin{abstract}
The article deals with the study of surface roughness of thin-walled houses bearing rollers for roller mills. The size and shape of the rear end housing was designed in order to measure the surface roughness of the inner cylindrical bearing surface with a wall thickness of 4, 5 and $6 \mathrm{~mm}$. For comparison the roughness was measured also on the wall with a thickness $26 \mathrm{~mm}$. The welded housing and the base plate was clamped in the machine vice jaw with a width of $150 \mathrm{~mm}$. Material components bearing small house has been fine-grain weld able steel bearing S355. For finishing the hole with a diameter of $40 \mathrm{~mm}$, a tool with a diameter of $32 \mathrm{~mm}$ was used with three cutting blades SDXT09M405R MM. Spindle speed was $1350 \mathrm{rev} / \mathrm{min}$. Tool feed speed was $850 \mathrm{~mm} / \mathrm{min}$. The surface roughness was measured with a Mitutoyo SJ 400th.
\end{abstract}

Keywords: thin wall, roughness, pipe conveyor, bearing houses.

\section{INTRODUCTION}

Thin-walled components are widely used in various industries. The main use is in the automotive, aviation, mining and energy industry. This industry is progressing rapidly, so the accuracy of these used parts also depends on their further development. Direct definition of thin-walled components is not yet determined. Among the essential characteristics include thin high walls used in a variety of shapes. The main use of these components is to replace the original technology of casting and molding parts with lighter, thinwalled components with sufficient strength and the same functionality made of machining technologies. The use of these components results in an overall reduction in mass assemblies, thereby reducing the number of production factors such as costs, installation time and many more.

Michalik et al. studied of surface roughness and analytical prediction of surface roughness $\mathrm{Rz}$ for variable geometrical parameters for thin wall components with thickness $10 \mathrm{~mm}$. In the first part they dedicated their research to experiments of manufacturing thin wall components, what was the basis for the design of these experiment? Experiments were conducted in two phases. The first was based on up milling and the second on down milling for left and right side of thin wall components with a thickness of $10 \mathrm{~mm}$. Subsequently, the surface roughness $\mathrm{Rz}$ was evaluated and was determined with mathematical equations for each type of milling, side and for each depth. Final output of the presented article is a mathematical model of surface roughness Rz prediction for constant cutting conditions, but for variable geometrical parameters of thin wall components [1, 14].

Molnar et al. investigated contact forces that are induced due to a reciprocal contact between the conveyor belt and forming idler rolls during operation of the pipe conveyors and the influence they have on the operational characteristics of these conveyors and the significance of the characteristics. Despite the frequent application of the 
pipe conveyors, the question of contact forces is often neglected. This paper analyses closely the contact force values and their dependence on tensional force in order to identify mutual relations taking into consideration the selected factors, acting on the bearing houses $[2,6,7]$.

Molnar et al. presented verification of the influence of tensile force emitted from the conveyor belt to the size of the contact forces that are induced by closed conveyor belt on the guide rollers clamped in bearing houses. The hexagonal cartridge was inserted in the tube conveyor. The conveyor belt is subject to the action of pulling force and it simultaneously focuses on the creation of downforce. The measured data is presented by conventional descriptive statistical characteristics and the comparison is used with nonparametric statistical methods for comparison of position and tensile strength $[3,8,9]$.

Molnar et al. analysed an impact of asymmetrical tension forces, which are occurring in the conveyor belt, on the contact forces in the guiding idlers clamped in bearing houses. It describes causes of an increased wear-out of the conveyor belts due to an asymmetric tensioning of the transport belt. There were investigated five measuring points loaded with a symmetrical and asymmetrical tensioning of a specimen section of the pipe conveyor transport belt, using the Friedman test for the factor of asymmetry. The tension force determines the changes of the contact force layouts in the individually investigated idler rolls. A newly developed method was applied in order to identify states of the particular experimental phases for the process of the transport belt tensioning and relaxation. This method is based on differences of the contact force time behaviours. It is possible to present a hypothesis, taking into consideration the obtained results that a side slipping of the running conveyor belt is caused by the tension force asymmetry also on the real operational conditions $[4,10,11]$.

Panda et al. described quality and accuracy in engineering by means of standards ISO. One of these standards is standard ISO 3685. The main part of this standard is T-ve dependence for various cutting materials. Standard ISO 3685 contains main properties and characteristics of three of the most important cutting materials used in engineering practice. These cutting materials are used for cutting tools made of high-speed steel, cutting ceramic and sintered carbide. The standard ISO 3685 prescribes instructions to creation of T-vc dependence for defined cutting materials.
The paper describes the process of how to define T-vc dependence for cutting tools made of high speed steel, cutting ceramic and sintered carbide, because were found deficiencies in valid standard ISO $3685[5,12,13]$.

\section{METHODS AND EXPERIMENTS}

The bearing house (Fig. 1) was designed so that the wall thickness of the finishing machining at the opening has a diameter of $40 \mathrm{~mm}$, on the left side of $6 \mathrm{~mm}$ (Fig. 2), on top $5 \mathrm{~mm}$, to the right $4 \mathrm{~mm}$. At the bottom it was designed with a dimension of $26 \mathrm{~mm}$. Clamping bearing small house was carried out in a vice with flat jaws. For the machining of the hole a $40 \mathrm{~mm}$ diameter tool was used (Fig. 3) of $32 \mathrm{~mm}$ with three cutting blades SDXT09M405R MM. Tools with cylindrical shank with two grooves were clamped by two clamping screws in short an arbor with a tapered shank SK 40. Cutting conditions were as follows for machining, spindle speed $1350 \mathrm{rev} / \mathrm{min}$. Tool feed speed was $850 \mathrm{~mm}$ / min. The surface roughness was measured with a Mitutoyo SJ 400 before the surface roughness was measured by a control measurement of roughness on the template, the values of $\mathrm{Ra} 2,94$ microns and the Rz 9,3 microns (Fig. 4 and 5). The material of the body rear end housing S355 was used for the chemical composition of Table 1.

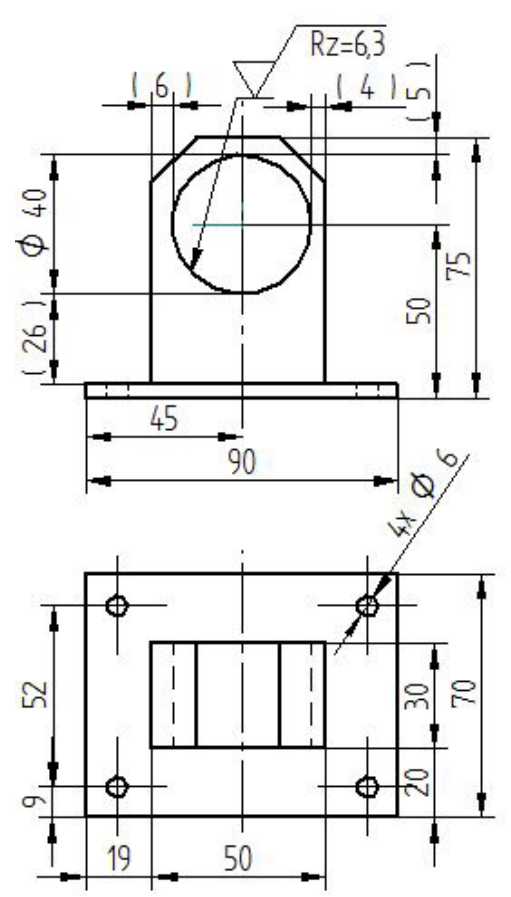

Fig. 1. Dimensions of the wall thickness of the bearing unit 
Table 1. Material properties

\begin{tabular}{|c|c|c|c|c|c|}
\hline Grade & $\mathbf{C}[\%]$ & Mn [\%] & $\mathbf{P}[\%]$ & $\mathbf{S}[\%]$ & Si [\%] \\
\hline \multirow{2}{*}{ S355 } & 0,23 & 1,6 max & $\begin{array}{c}0,05 \\
\max \end{array}$ & $\begin{array}{c}0,05 \\
\max \end{array}$ & $\begin{array}{c}0,05 \\
\max \end{array}$ \\
\hline
\end{tabular}

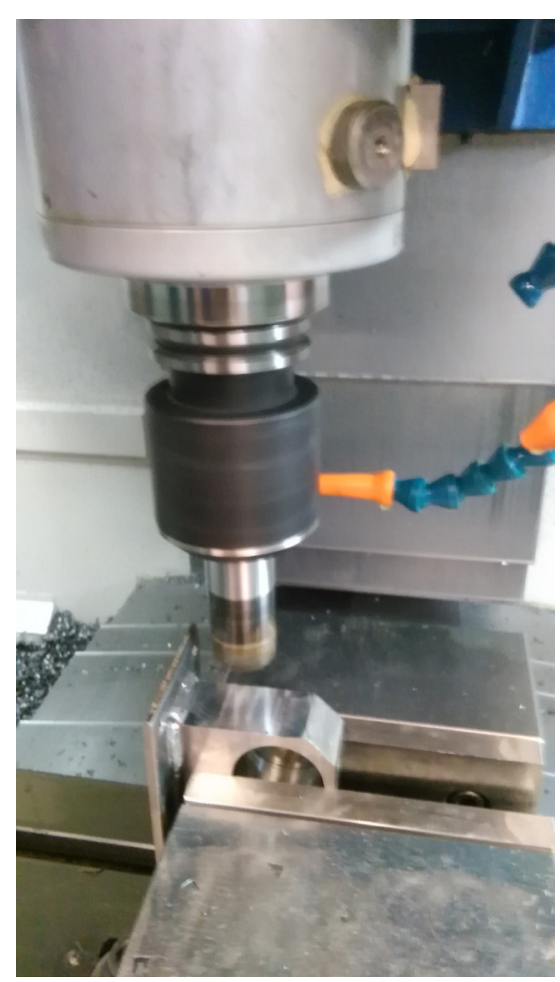

Fig. 2. Machining walls bearing unit with $6 \mathrm{~mm}$ thick

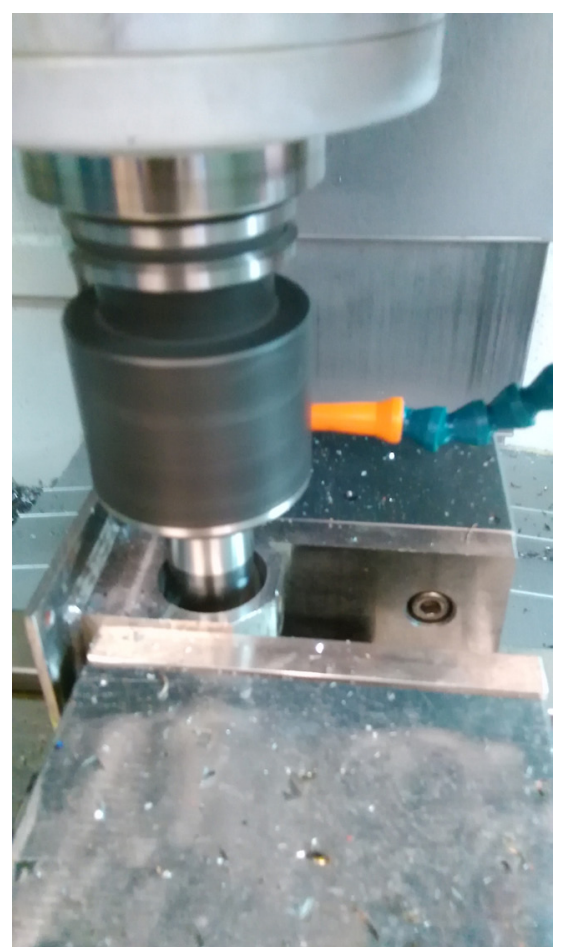

Fig. 3. Machining hole diameter $40 \mathrm{~mm}$ by the tool with diameter $32 \mathrm{~mm}$

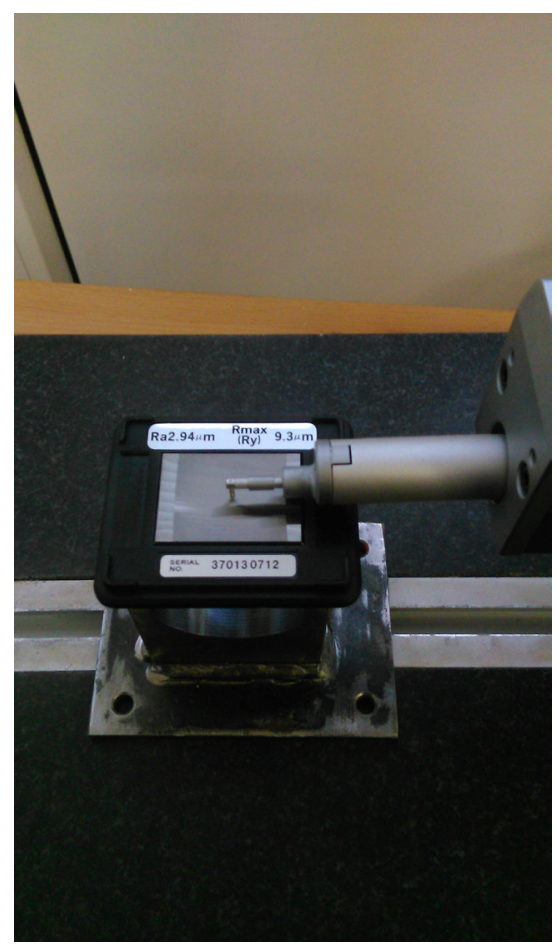

Fig. 4. Control roughness measurement on the template

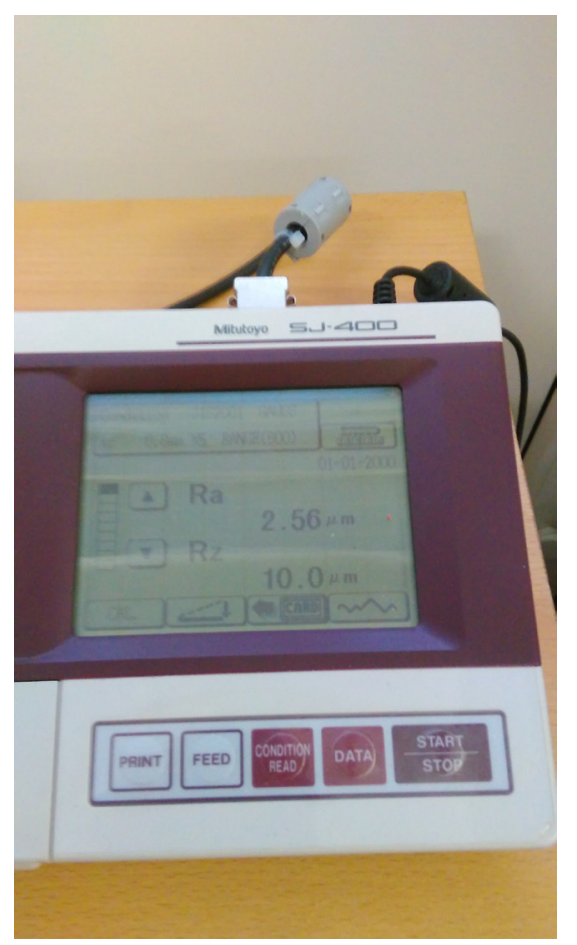

Fig. 5. Readings of roughness on a template

The roughness measurements were realized on the 10 consecutive points on the $30 \mathrm{~mm}$ width of the rear end housing to a wall thickness of 6 $\mathrm{mm}$ (Fig. 6), for a wall thickness of $5 \mathrm{~mm}$ (Fig. 7), the wall thickness of $4 \mathrm{~mm}$ (Fig. 8). 


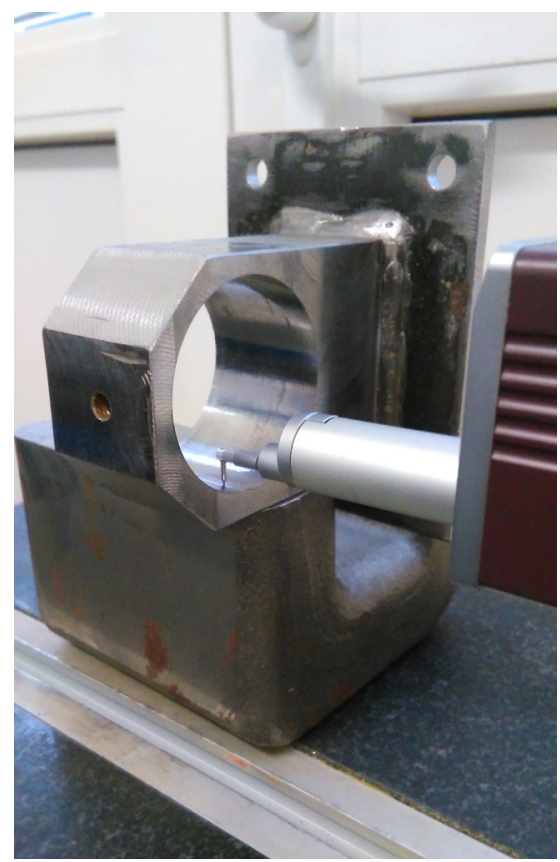

Fig. 6. Measuring of roughness with $6 \mathrm{~mm}$ thick

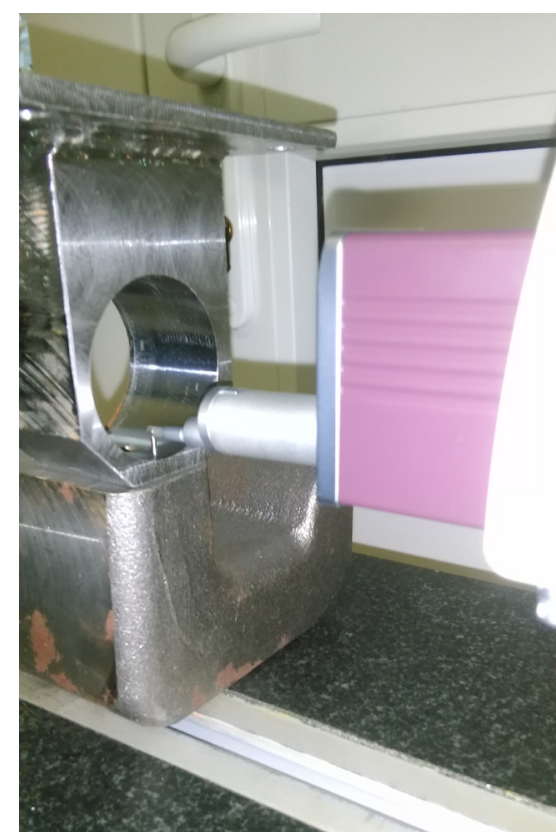

Fig. 7. Measuring of roughness with $5 \mathrm{~mm}$ thick

\section{RESULTS AND DISCUSSION}

The resulting roughness were compared to the same measurement sites for different wall thicknesses bearing house. Figure 9 compares the roughness of the walls with a thickness of 4, 5 and $26 \mathrm{~mm}$. The lowest value of $\mathrm{Ra}$ of 0.58 microns to a wall thickness of $4 \mathrm{~mm}$ was measured at a length of $2 \mathrm{~mm}$. Similarly, the same result was for the wall with the thickness $5 \mathrm{~mm} \mathrm{Ra}=0,5$

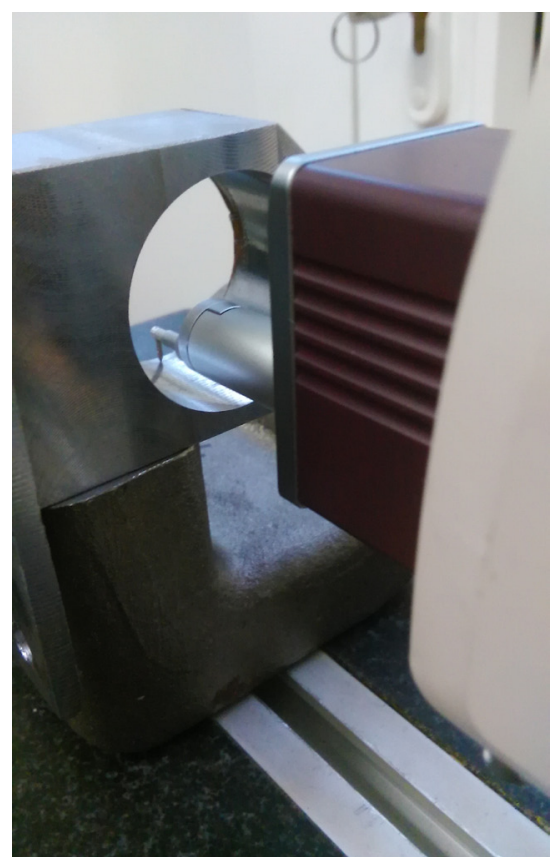

Fig. 8. Measuring of roughness with $4 \mathrm{~mm}$ thick

microns. The lowest value of Ra of 0.47 microns to $26 \mathrm{~mm}$ wall was measured to a length of $5 \mathrm{~mm}$. The highest value $\mathrm{Ra}$ of 0.88 microns for a wall with the thickness $4 \mathrm{~mm}$ was measured at a length of $29 \mathrm{~mm}$. On the wall of $5 \mathrm{~mm}$ thickness was Ra $=0.94$ microns to $5 \mathrm{~mm}$ in length. The highest value of $\mathrm{Ra}=0.79$ microns to $26 \mathrm{~mm}$ wall was measured on a length of $26 \mathrm{~mm}$. The smallest difference in roughness $\mathrm{Ra}=0.01$ was for the walls with the thickness 4 and $5 \mathrm{~mm}$ to a length of 11 $\mathrm{mm}$. The biggest difference $\mathrm{Ra}$ of 0.32 microns was on the walls with thickness $4 \mathrm{~mm}$ and $5 \mathrm{~mm}$ at a length of $5 \mathrm{~mm}$.

Figure 10 compares roughness on the walls with a thickness of 5,6 and $26 \mathrm{~mm}$. The lowest values $\mathrm{Ra}=0.43$ microns to $6 \mathrm{~mm}$ wall thickness was measured in length of $8 \mathrm{~mm}$. The highest value of $\mathrm{Ra}=0.89$ microns to $6 \mathrm{~mm}$ wall thickness was measured at a length of $23 \mathrm{~mm}$. The smallest difference in roughness $\mathrm{Ra}=0.05$ microns was for the wall with thickness of 5 $\mathrm{mm}$, and 6 , to a length of $14 \mathrm{~mm}$. The highest difference $\mathrm{Ra}=0.43$ microns was for the walls with a thickness of 5 and $6 \mathrm{~mm}$ in length $5 \mathrm{~mm}$. Figure 11 compares roughness on the walls with a thickness of 4, 6 and $26 \mathrm{~mm}$.

The smallest difference in roughness $\mathrm{Ra}=$ 0.06 was for the wall with thickness $4 \mathrm{~mm}$ and $6 \mathrm{~mm}$ on a length of $2 \mathrm{~mm}$. The biggest difference Ra of 0.27 microns was on the walls with the thickness of $4 \mathrm{~mm}$, and 6 , to a length of $23 \mathrm{~mm}$. 


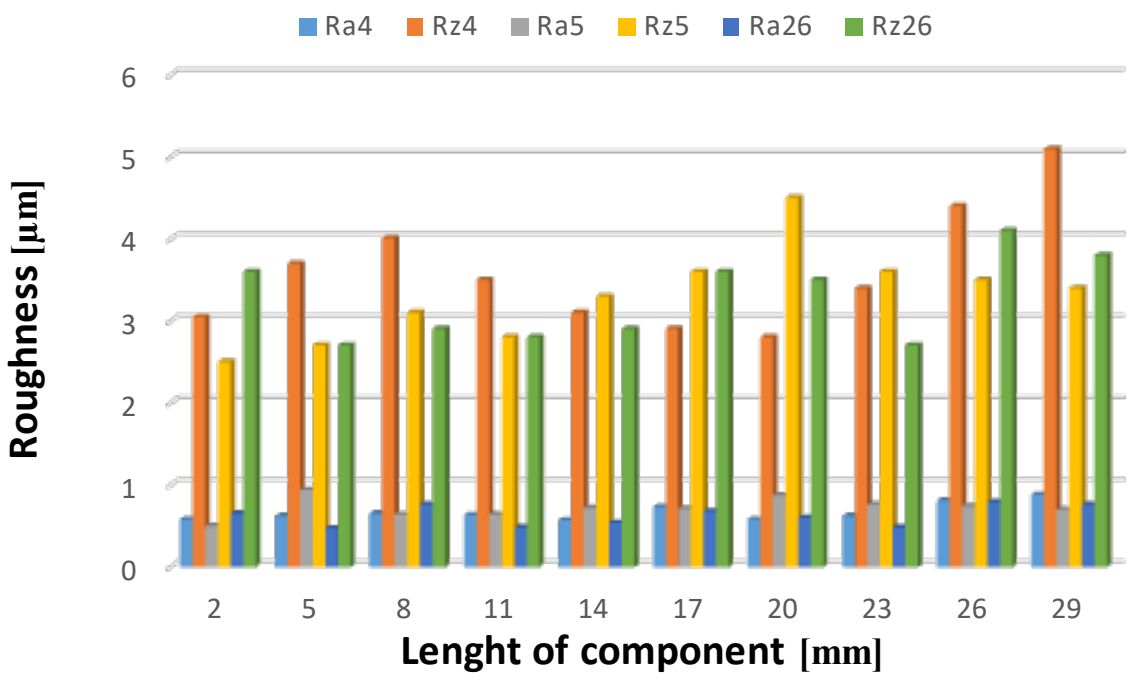

Fig. 9. Comparison of roughness on the walls with a thickness of 4, 5 and $26 \mathrm{~mm}$

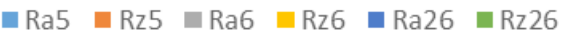

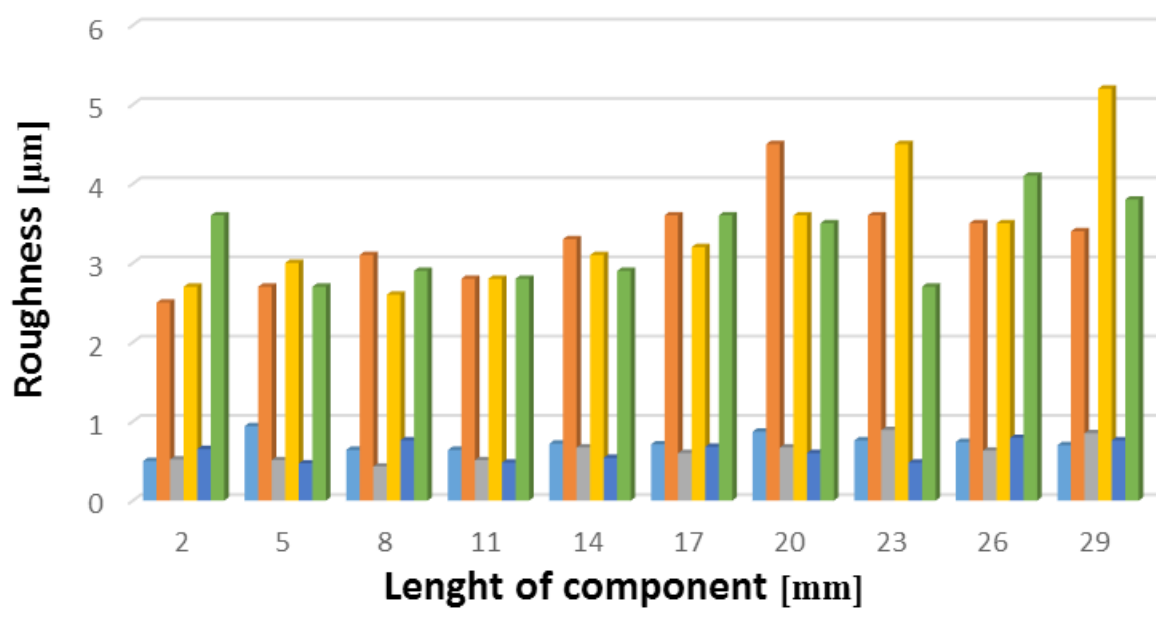

Fig. 10. Comparison of roughness on the walls with a thickness of 5,6 and $26 \mathrm{~mm}$

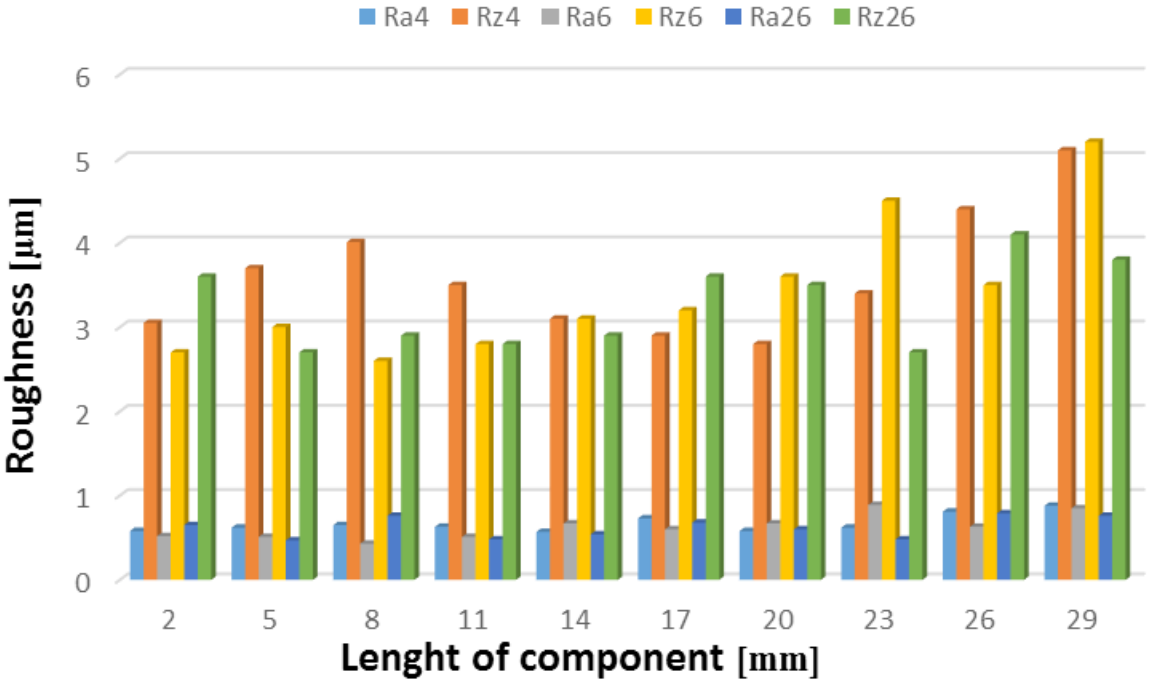

Fig. 11. Comparison of roughness on the walls with thickness of 4, 6 and $26 \mathrm{~mm}$ 


\section{CONCLUSION}

The features, functionality and free surfaces of components greatly influence the nature of the surface of the components, which is one of the parameters determining the applicability of the various parts in different assemblies. Selected surface characters and the required tolerances in the manufacture of components to us affects the price, durability, function and appearance of the individual parts and assemblies. Surface roughness of free components affects various properties such as appearance, corrosion resistance and thermal conductivity. The roughness of each other moving surfaces affects the functional loss caused by friction, lubrication function, wear resistance, impact protection and the service life of components. There is a need to make the desired surface roughness prescribed in the drawing part in the standards and technical conditions. From a comparison of the measured values it can be concluded that the lowest values of roughness were measured in the walls of the working length of $2 \mathrm{~mm}$ and a maximum value of the length of 28 $\mathrm{mm}$ working, due to decreasing rigidity of the machined surfaces. Minimum roughness average of the values was calculated for a wall thickness of $6 \mathrm{~mm}$. This thickness is also recommended for serial production houses bearing rollers for roller seats pipe conveyors.

\section{Acknowledgements}

This work is a part of research project VEGA $1 / 0619 / 15$.

\section{REFERENCES}

1. Michalik P., Zajac J., Hatala M., Mital D., Fecova $\mathrm{V}$. Monitoring surface roughness of thin-walled components from steel $\mathrm{C} 45$ machining down and up milling, Measurement. 58 (2014), 416-428.

2. Molnár V., Fedorko G., Andrejiová M., Grinčová A., Kopas M. Monitoring of dependences and ratios of normal contact forces on hexagonal idler housings of the pipe conveyor, Measurement. 64 (2015), 168-176.

3. Molnár V., Fedorko G., Stehlíková B., Kudelás L., Husáková N. Statistical approach for evaluation of pipe conveyor's belt contact forces on guide idlers, Measurement. 46 (2013), 3127-3135.
4. Molnár V., Fedorko G., Stehlíková B., Tomašková M., Hulínová Z. Analysis of asymmetrical effect of tension forces in conveyor belt on the idler roll contact forces in the idler housing, Measurement. 52 (2014), 22-32.

5. Panda A., Duplák J., Vasilko K., Analysis of Cutting Tools Durability Compared with Standard ISO 3685, Int. J. Comput. Theory Eng. 4 (2012), 621-624.

6. Molnar V., Fedorko G., Stehlikova B., Paulikova A. Influence of tension force asymmetry on distribution of contact forces among the conveyor belt and idler rolls in pipe conveyor during transport of particulate solids. Measurement (2015), 120-127.

7. Fedorko G., Molnar V., Dovica M., Toth T., Kopas M. Analysis of pipe conveyor belt damaged by thermal wear, Engineering Failures Analles 45 (2014), 41-48.

8. Lumnitzer E., Liptai P., Drahos R. Measurement and Assessment of Pulsed Magnetic Fields in the Working Environment, in: Kolcun, $\mathrm{M}$ and Kolcunova, I and Kurimsky, J (Ed.), Proc. 8TH Int. Sci. Symp. Electr. Power Eng. (Elektroenergetika 2015), 2015, 331-333.

9. Stejskal T., Kelemenová T., Dovica M., Demeč P., Štofa M. Information contents of a signal at repeated positioning measurements of the coordinate measuring machine (CMM) by laser interferometer. In: Measurement Science Review. Vol. 16, no. 5 (2016), 273-279.

10. Gajdoš I., Slota J., Spišák E., Jachowicz T., TorŚwiątek A. Structure and tensile properties evaluation of samples produced by Fused Deposition Modeling. Open Engineering - 2016, nr 1, vol. 6, 86-89.

11. Mantic M., Kulka J., Krajnak J., Kopas M., Schneider M. Influence of selected digitization methods on final accuracy of 3D model, Production Management and Engineering Sciences. - Leiden : CRC Press/Balkema, 2016, 475-480.

12. Strohmandl J. Use of simulation to reduction of faulty products. Scientific Bulletin Series D: Mechanical Engineering. 3/2014, 2286-3699.N

13. Němčěk O., Honus S., Juchlková D. Application and Efficiency Verification of Classical and Unconvetional Sorbents which Serve for Capture of Heavy Metals during Coal Combustion in Experimental Fluid Device. Applied Mechanics and Materials, Vols. 260-261 (2013), 302-306.

14. Rozbroj J., Zegzulka J., Nečas J. Use of DEM in the Determination of Friction Parameters on a Physical Comparative Model of a Vertical Screw Conveyor, Chem. Biochem. Eng. Q. 29 (2015), 25-34. 